\title{
ON MOORING DESIGN OF WAVE ENERGY CONVERTERS: THE SEABREATH APPLICATION
}

\author{
Luca Martinelli $^{1}$, Piero Ruol ${ }^{1}$ and Giampaolo Cortellazzo ${ }^{1}$
}

\begin{abstract}
The design of a mooring system of a Wave Energy Converter is a challenging process that points out several unsolved technical problems, mostly related to the highly non-linear hydrodynamic phenomena occurring when high waves (e.g. $8 \mathrm{~m}$ high with $200 \mathrm{~m}$ wavelength) propagate in relatively shallow waters (e.g. $20 \mathrm{~m}$ ). The aim of this note is to point out the relevance of the non-linear response of a WEC anchored in relatively shallow waters (shallow in the "non-linear" sense) in terms of loads applied to the mooring lines. Further, the effects of this cyclic load on the anchors is investigated. Note that to some extent it is like checking the importance of geotechnical and coastal engineers in the design process of the WEC structure and its mooring system (typically carried out by naval architects). The whole mooring design process is first outlined and then it is schematically applied to a specific case, namely a promising Italian device named SeaBreath (www.seabreath.it), in view of a possible deployment in the Adriatic Sea. The main concern of mooring designers is related to resonance effects induced by the second order drift. Therefore specific tests have been carried out in the $36 \mathrm{~m}$ long x $1.0 \mathrm{~m}$ wide $\times 1.3 \mathrm{~m}$ high wave flume of Padova University. Tests focused on the forces on the mooring lines induced by the sum of two regular waves of similar frequency. The mooring design is still far from complete: the physical model proved the relevance of the aforementioned effects but a numerical investigation (not yet performed) is required to draw final conclusions.
\end{abstract}

Keywords: mooring system design; anchor design; fluid-structure-foundation interaction

\section{INTRODUCTION}

Wave Energy Converters (WECs) are at an early stage of development. First generation devices have been deployed at the shoreline. Unfortunately, such devices have a strong environmental impact and their potential in harvesting wave energy is limited due to the significant losses occurring in the surf zone.

Second generation devices are floating WECs (F-WECs) located in the near-shore area, i.e. at water depths where both piles or mooring lines may be alternatively used. They are just out of the surf zone, where the available energy is only slightly smaller than in the off-shore areas. The environmental impact is still to be evaluated in detail but at least they are almost invisible from shore.

This note addresses the mooring system of F-WECs. The mooring design process has been developed in the engineering field for some years by the experience from offshore structures (Isaacson \& Nwogu, 1987) and shipbuilding. Despite this fact, a relatively high rate of floating WECs have failed in their efforts because the mooring system was unable to anchor. Lack of reliability follows from unsolved technical problems related to the environment where WECs are deployed. Differently from ships, the hydrodynamic process is highly non-linear, since high waves (e.g. heights $H=8 \mathrm{~m}$ with wavelength $L=200 \mathrm{~m}$ ) propagate in relatively shallow waters (e.g. depth $h=20 \mathrm{~m}$ ).

The aim of this note is to assess the relevance of the non-linear response of a F-WEC anchored in relatively shallow waters (shallow in the "non-linear" sense, i.e. high $H / h$ ) in terms of loads applied to the mooring lines. The effects of this cyclic load on the anchors are also investigated. Note that to some extent it is like checking the importance of geotechnical and coastal engineers in the design of the FWEC structure and its mooring system (typically carried out by naval architects).

In the following, first the whole process for mooring design is outlined. Then, a specific application is introduced, the SeaBreath (www.seabreath.it), in the framework of a research that focuses on small WEC devices (Martinelli, 2011). The main concern of mooring designers of the SeaBreath is related to the response in resonant conditions. Mooring loads are therefore studied by means of specific physical model tests carried out in the $36 \mathrm{~m}$ long x $1.0 \mathrm{~m}$ wide x $1.3 \mathrm{~m}$ high wave flume of Padova University. In the laboratory, long period resonant oscillations are induced by generating pairs of waves having similar frequency. Forces on the mooring lines of a catenary spread mooring system are measured.

\section{MOORING DESIGN PROCEDURE}

Floating Wave Energy Converters (F-WECs) require a mooring system in order to ensure station keeping, and more specifically to limit the drift, ensure alignment of directional WECs with the

${ }^{1}$ ICEA Department, University of Padova, V. Ognissanti 39, Padova, 35129, Italy 
prevailing wave conditions, avoid impact with other structures (Fitzgerald, 2009) and excessive loads on the electric power umbilical (Martinelli et al, 2010a).

In details the requirements are:

- to maintain the floating structure on station within specified tolerances under normal operating load and extreme storm load conditions, that is generally more severe and frequent than for normal mooring installations;

-the excursion of the device must not permit tension loads in the electrical transmission cable(s) and should allow for suitable specified clearance distances between devices in multiple installations; contact between mooring lines, or contact with the device itself must be avoided;

- the mooring system must be sufficiently compliant to the environmental loading to reduce the forces acting on anchors, mooring lines and the device itself to a minimum (unless the stiffness of the mooring itself is an active element in the wave energy conversion principle used);

-the mooring have to be sufficiently compliant to accommodate the tidal range at the installation location, and sufficiently stiff to allow berthing for inspection and maintenance purposes.

The mooring system should also require as little inspection and maintenance as possible over the in-service life of the device. It should be possible to remove the F-WEC from the site (or remove one FWEC from energy farm), with easy re-installation, without damaging any components or reducing the service life of the system.

The system should limit the environmental impact as much as possible. Environmental factors to be considered include damage to the local environment, visual impact, and any effect on the local ecosystem.

The design process concerns the configuration of the individual lines, their interaction with the bottom (through piles, drag embedded, gravity or plate anchors), and the overall layout, i.e. the disposition of the lines that is responsible of the correct orientation of the F-WEC relatively to the predominant waves and of the possible weathervaning.

The design procedure includes design and verification phases (Fig.1).

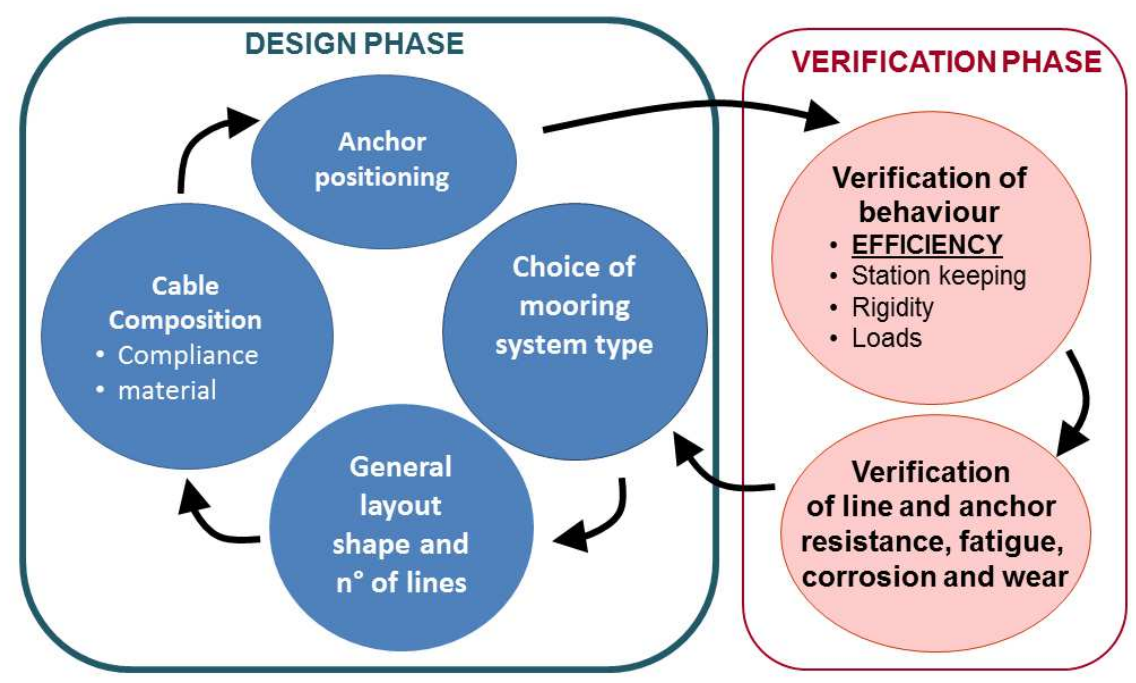

Figure 1. Proposed mooring design method.

\section{DESIGN OF ANCHORING SYSTEM}

In first approximation, the design assume that anchors are fixed at the bottom, so the effects due to the movement associated with possible deformation of the anchorage soil during storm loading are not taken into account.

Actually, depending on the load and on the type of soil, typically clay or sand, there may be some anchor movements, that may be predicted with a relationship between line tension, anchor penetration depth and drag.

Therefore, the design should be able to take into account mainly:

-the effect on anchor resistance of soil consolidation from the time of anchor installation until the occurrence of the design event and the creep effects, especially in clayey soils; 
-the effects on the anchor resistance of cyclic loading, i.e. the combined effect of loading rate and cyclic degradation.

During continuous penetration of a fluke anchor in clay, some excess pore pressure occurs around the anchor and the friction resistance between the fluke anchor walls and the surrounding soil will be governed by the remoulded shear strength in a narrow zone close to the anchor. Thereafter, the setup and shear strength increase in the soil at the wall of a fluke anchor occur due to dissipation of excess pore pressure; moreover thixotropy can occur since the softening caused by remoulding during penetration return to the original harder state at a constant water content and constant porosity. Both effects result in significant strength gain, but they should not be considered additive.

Centrifuge tests have also shown a reduction in operative shear strength resulting from the slow displacement rate of the anchor due to sustained load larger than $85 \%$ of the monotonic ultimate capacity. Therefore only sustained load lower than $85 \%$ should be allowed (Wong et al, 2012).

The effects of cyclic loading on soil strength derive from several aspects: peak cyclic value load, equivalent number of cycles, loading rate (Andersen, 2009).

Since the behavior of soils is highly site specific and consequently each project should gain accurate specific soil information, the general behavior can be defined only in a qualitative way.

Several studies, based on the laboratory test results carried out on clay and sand with Direct Simple Shear (DSS) and cyclic triaxial device, have shown the existence of particular combinations of average values and cyclic shear stresses that will cause failure in a given number of cycles.

In clay the cyclic shear strength at failure $\tau_{\mathrm{f}, \mathrm{cy}}$ is lower than static shear strength $\mathrm{s}_{\mathrm{u}}$ if the equivalent number of cycles is greater of about 8 or the average shear stress at failure $\tau_{\mathrm{a}, \mathrm{f}}$ is greater than 0.6 of $\mathrm{s}_{\mathrm{u}}$.

Similar results have been achieved by analyzing the data of a series of centrifuge tests undertaken to investigate the performance of a model SEPLA (suction plate embedded anchors) in clayey soil. In this case, however, failure occurred for any loading where the peak load exceeded $75 \%$ of the monotonic capacity. With peak cyclic load up to $75 \%$ of the maximum pull-out capacity, the anchor experienced limited displacement, stabilizing with increasing cycles.

Results of cyclic laboratory tests carried out on sand specimens show a marked decrease of the cyclic resistance with an increasing number of cycles to failure and in the presence of a preshearing (small cyclic shear stresses accompanied by drainage prior to the main design event) causing large shear strain. Instead, for a given number of cycles to failure, the cyclic shear stress at failure increases if the preshearing causes small shear strain.

\section{APPLICATION}

\section{The Seabreath}

The Seabreath is a multi chamber WEC that utilizes the "oscillating water columns" concept to harvest wave energy (www.seabreath.it). The device is a floating elongated body divided into chambers open below and connected by two air ducts equipped with non-return valves. The passage of a wave creates different levels inside the chambers so that the air inside is compressed or decompressed. In the chambers where the water level rises, the air enters one duct (say, the first) duct, and where the level falls, the air is sucked from the second duct. Additional external retention valves compensate for the changing volumes of air/water inside the system. The two ducts are separated by an air turbine, that generates energy by the pressure difference.

In short, a number of non-return valves are arranged in a way to keep the first duct at a pressure larger than the chambers (or the atmospheric pressure) and the second duct at a pressure smaller than the chambers (or atmosphere), so that air flows from the first to the second duct and drives an air turbine.

In order to optimize the power of the wave, the length of the device must be at least equal to the length of the wave to be harnessed. The advantage of the Seabreath is to produce a continuous and unidirectional flow of air, allowing for the use of high efficient impulse turbine in contrast to Wells turbine. 
It is planned to build a $37 \mathrm{~m}$ long device built with recycled containers. A possible deployment is the Adriatic Sea. Recently, the oceanographic CNR platform "Acque Alte" examined the possibility to host WEC defaces for research testing purposes.

Water depth at the platform is approx. $16 \mathrm{~m}$, with sandy bottom, incident wave energy $2 \mathrm{~kW} / \mathrm{m}$ in average. Design maximum wave is of order $5 \mathrm{~m}$.

\section{Design phase: choice of mooring system type}

According to Fig. 2, the first step of the design phase is the choice of the mooring system type. This has to be done by selecting the best of several alternatives (Harris et al., 2004).

It is useful to be guided by a proper functional and geometrical classification for mooring types (presented in Fig. 2). The geometrical classification is traditional, and self-explicatory. On the contrary, the functional classification requires at least a brief description:

1. Passive mooring, if the station keeping is the only purpose and movements have a limited effect on the device efficiency.

2. Active mooring, if the system stiffness is an important factor for the dynamic response of the device. Such effects can offer resonance conditions in order to produce much more energy;

3. Reactive mooring, if the mooring provides a reaction force. They are suited especially when the Power Take Off (PTO) exploits the relative movements between the body and the fixed ground.

\begin{tabular}{|c|c|c|c|c|}
\hline \multicolumn{2}{|c|}{ Spread mooring } & $\begin{array}{c}\text { Passive } \\
\text { mooring }\end{array}$ & $\begin{array}{c}\text { Active } \\
\text { mooring }\end{array}$ & $\begin{array}{c}\text { Reactive } \\
\text { mooring }\end{array}$ \\
\hline \multicolumn{2}{|c|}{ Turret mooring } & & & \\
\hline \multirow{3}{*}{$\begin{array}{c}\text { Single } \\
\text { Point }\end{array}$} & Catenary Anchor Leg Mooring (CALM) & & & \\
\cline { 2 - 5 } & Single Anchor Leg Mooring (SALM) & & \\
\cline { 2 - 5 } & Articulated Loading Platform (ALP) & & \\
\cline { 2 - 5 } & Fixed mooring tower & & & \\
\hline
\end{tabular}

Figure 2. Comparison of the functional and geometrical classification.

A list of possible alternatives were identified. Some of the alternatives are presented in Fig. 3. It is easy to recognize that cases $a, b, c$ are typical passive moorings, $e$ and $g$ are potentially reactive (potentially in the sense that the WEC should be able to use the reaction force), $d$ and $f$ are potentially reactive (if resonance conditions are achieved).

\section{Design phase: choice of layout}

The chosen mooring system is the spread mooring (Fig. 3 b). A peculiar design is considered, where the lines at rest all converge to an imaginary point placed in front of the buoyancy center. The system is capable of providing a certain wethervaning effect as shown in Fig. 4: for waves arriving obliquely with respect to the main incident direction, the system needs to rotate accordingly in order to reestablish the equilibrium of torque. 
a)

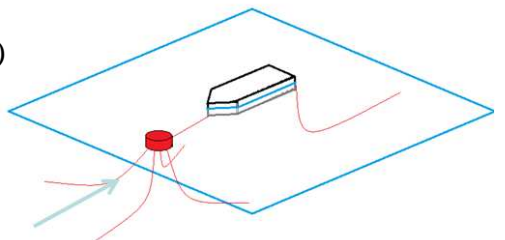

c)

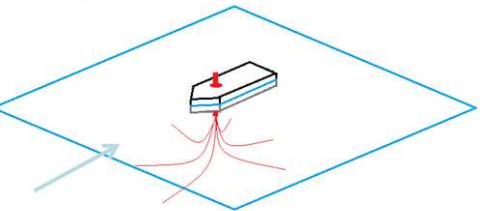

b)

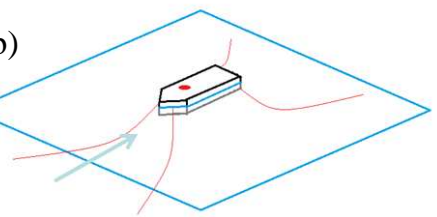

d)

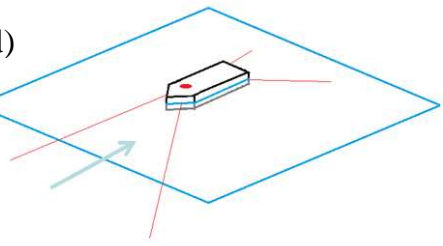

e)

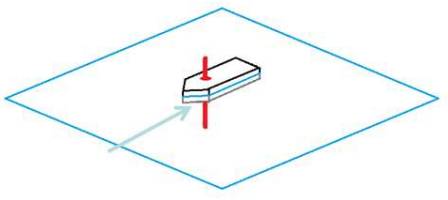

g)

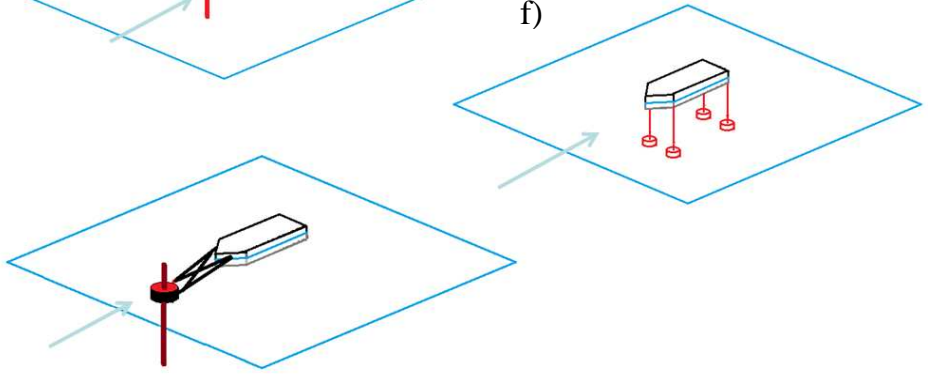

f)

Figure 3. Examples of possible alternatives for mooring systems. From top-left to bottom-right: a) CALM; b) spread; c) Turret; d) Tethered; e) Pile, allowing for weathervaning; f) Tethered, pre-stressed; g) Articulated leg.

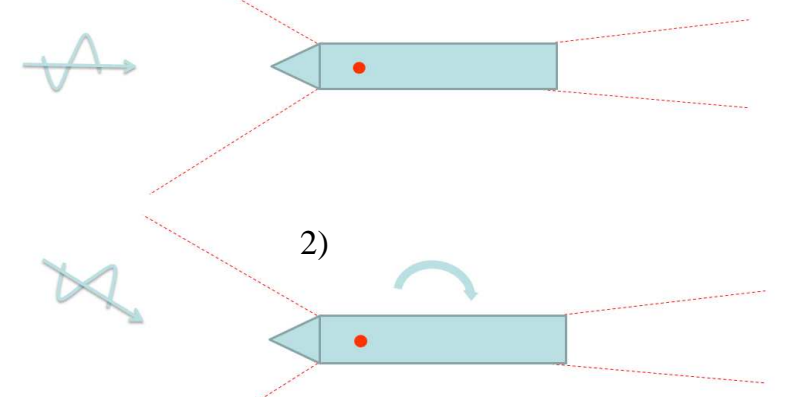

3)

Figure 4. Selected spread mooring and weathervaning mechanism. 1) Device aligned with principal sector; 2) As the wave direction changes, a torque is applied; 3) The torque is balanced by the mooring line reaction, if the device rotates aligning almost completely to the new wave direction. 


\section{Design phase: choice of cable composition}

The preliminary mooring system (Fig. 5) needs to be slightly different between the front and the rear, in order to follow the conceptual design indicated above. The two front chains are connected to a fairlead located almost in the front centerline, diverge $25^{\circ}$, are composed of $83 \mathrm{~m}$ long studless chains, diameter $36 \mathrm{~mm}$, grade R5, and the system also includes four shackles and two drag embedded anchors described below. In the rear part, the lines are $79 \mathrm{~m}$ long, divergence is $6^{\circ}$, fairleads are separate and located at the corners. The chains are preliminarily dimensioned for a load of $30 \mathrm{t}$, with $\phi 36$, weight $27.2 \mathrm{~kg} / \mathrm{m}$

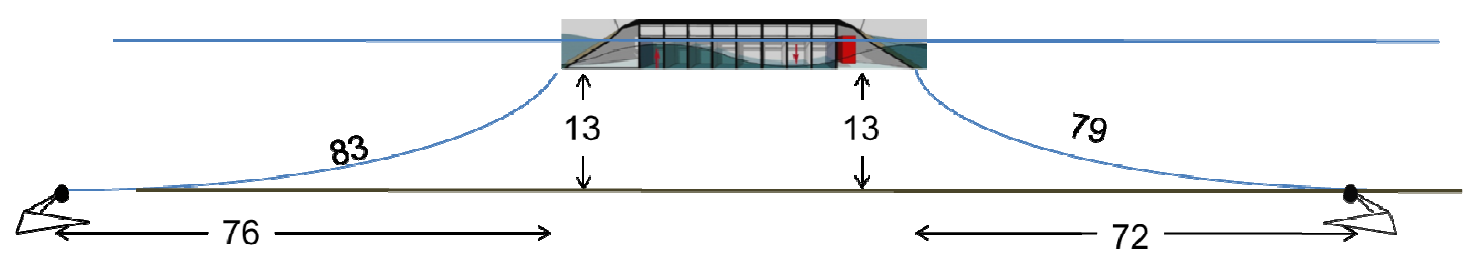

Figure 5. Cable composition

\section{Design phase: choice of anchor}

The anchor should have sufficient holding capacity to keep the WEC device on station for the duration of the design life, for all design conditions. The structural strength of the anchor for long term mooring must be designed for a design load equal to the characteristic breaking strength of the mooring line. The anchor design must be suited to the specific soil (sand and hard clay). The selected type is shown in Fig. 6.

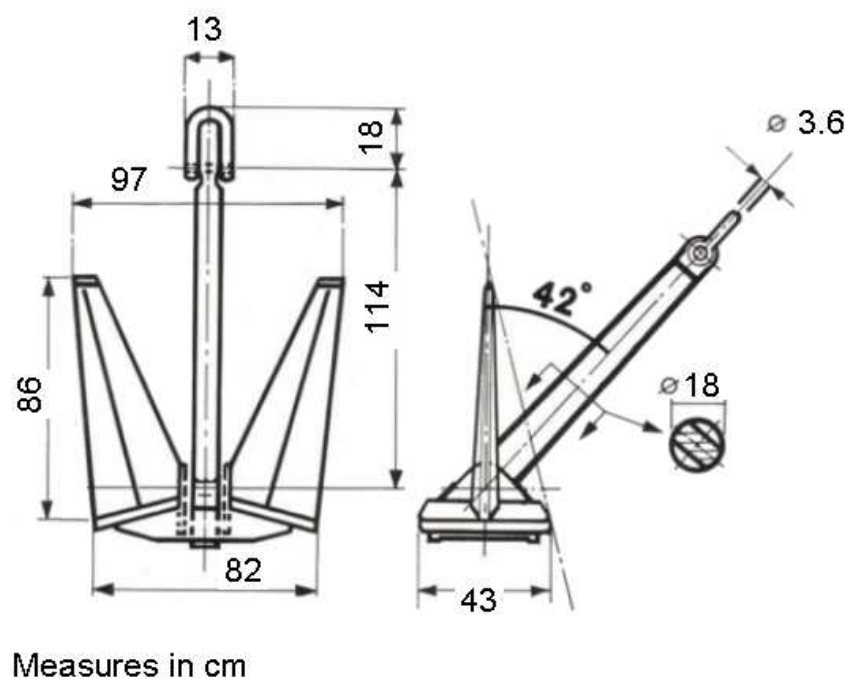

Figure 6. Selected anchor

\section{Mooring equipment costs}

The preliminary (conservative) design of the mooring system of the SeaBreath described above is computed for ULS load of order $50 \mathrm{t}$.

It is usually assessed that costs for mooring cover $30 \%$ of the whole budget.

Order of magnitude of the mooring costs are:

- studless chain for permanent moorings $\phi 36,\left(10^{\prime} 000 € / 100 \mathrm{~m}\right)$; weight $27.2 \mathrm{~kg} / \mathrm{m}$

- hot dip galvanised anchors (5,000 €/each), 0.32 tons

- galvanised swivel (2’000 €/each)

- Kenter shackle with load cell (3’000 €/each) 
The cost for the four mooring lines becomes approximately 80'000 €. Installation requires the use of a handling anchor vessel, with crane capable of lowering $16 \mathrm{~m}$ of chains plus anchor (for a total of just under 1 ton), not available at the CNR, for a fee of 10'000 €/day.

The resulting total cost is therefore approximately 90'000 €. This is significant part of the total cost of the Sea-Breath, in agreement with expectations.

\section{Verification phase}

The specific design is obtained, according to Fig. 2, in an iterative procedure involving the verification phase, accounting for the fluid-line interactions (Kreuzer and Wilke, 2003; Martinelli et al., 2010b). Fig. 7 gives the step used to carry out the verification phase.

In particular, the designers are concerned about possible errors in the evaluation of the mooring loads when the floating body oscillates in resonant conditions. In short, the device mooring stiffness and mass form a dynamic system (Loukogeorgaki et al., 2005) that, if appropriately forced, may show large oscillations in surge, which correspond to large quasi-static loads on the mooring lines. Although the forcing sea state has almost no energy at the resonant frequency, there may be a large load due to second order horizontal load.

The second order load is usually obtained by an irrotational flow model. The second order load is given by the following five second order terms, that represent the contribution of the square of the wave amplitude, the square of the velocity, the contribution of in phase displacements and oscillations, and the actual second order potential (Pinkster, 1980):

$$
\begin{aligned}
& \bar{F}^{(2)}=-\oint_{w l} \frac{1}{2} \rho g\left(\eta_{R}^{(1)}\right)^{2} \bar{n} d l+ \\
& \oint_{S o} \frac{1}{2} \rho\left|\nabla \Phi^{(1)}\right|^{(2)}+\rho\left(\bar{X}^{(1)} \bar{\nabla} \Phi_{t}^{(1)}\right) \bar{n} d S \\
& +\bar{\alpha}^{(1)} \times\left(M \ddot{\bar{X}}^{(1)}\right)+\oint_{S o}\left(\rho \Phi_{w, t}^{(2)}+\rho \Phi_{d, t}^{(2)}\right) \bar{n} d S
\end{aligned}
$$

Where the number in parenthesis give the order of approximation, $F$ is the load, $\eta$ is elevation, $\phi$ is potential, $w l$ is the waterline, $S_{\mathrm{o}}$ the wetted surface at rest, $X$ and $\alpha$ are the displacements and rotations vector, $M$ is the floating body mass.

In presence of small waves, the fifth term in Eq. (1), the only one depending on the second order potential, is negligible, and a first order solution is sufficient. Unfortunately, in case of WEC such term cannot be solved. Furthermore, in presence of a set of chambers, each with its degrees of freedom, the solution of first and second order potentials is more complex. Commercial irrotational flow codes do not converge easily.

The proposed solution is to carry out the design with a ship-type device, i.e. in absence of internal water chambers, and check the result reliability in presence of the resonant effects by means of physical model tests. 


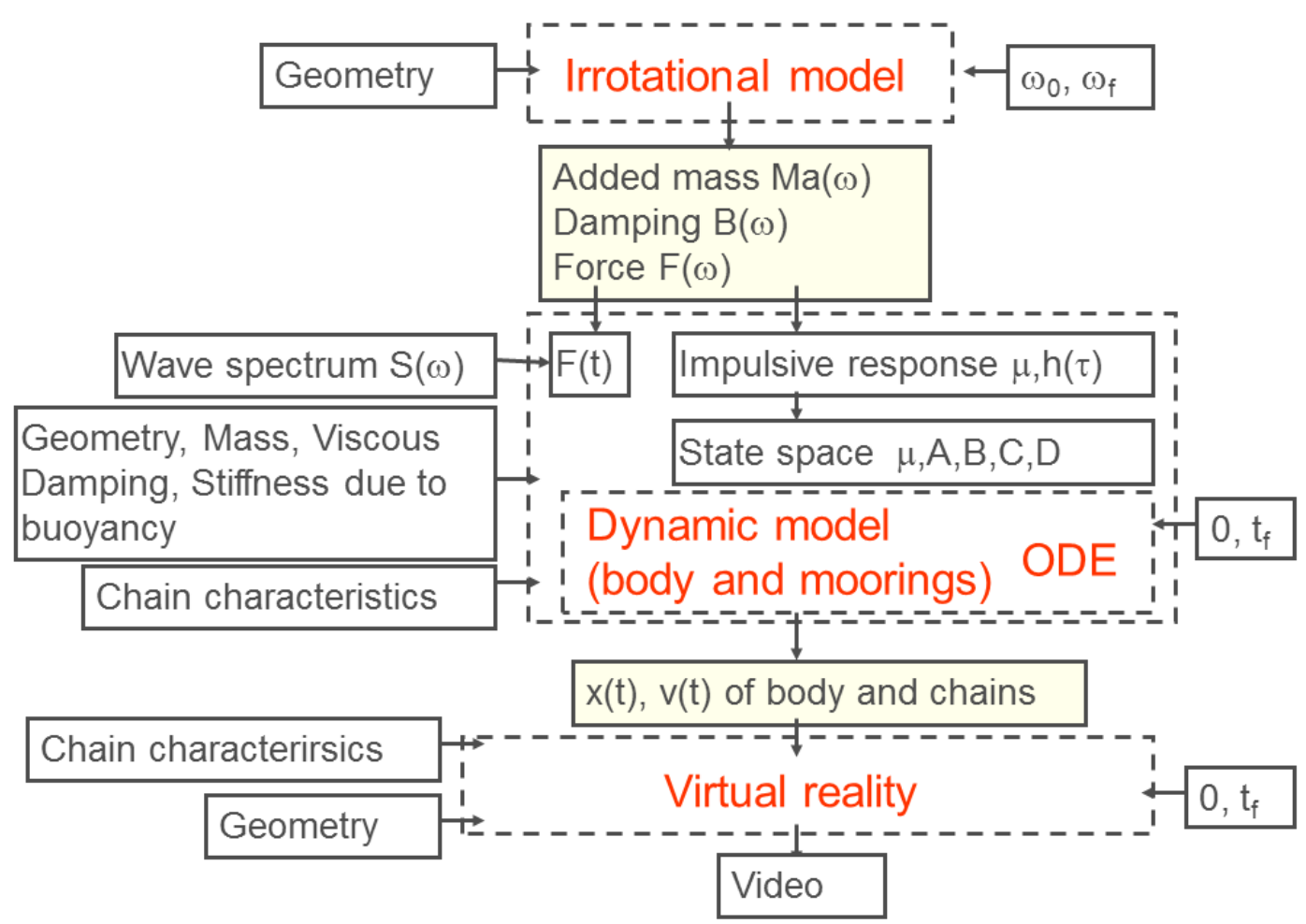

Figure 7. Layout of numerical models.

\section{PHYSICAL MODEL TESTS}

Physical model tests were carried out in the $36 \mathrm{~m}$ long x $1.0 \mathrm{~m}$ wide $\mathrm{x} 1.3 \mathrm{~m}$ high wave flume of Padova University on a second generation SeaBreath device. Compared to the first generation device, tested by the authors in the same facility, the pipeline hosting the wave energy converter and the valves have double cross section.

The tests are carried out in approximate scale 1:20 with reference to the CNR application site. Some constraints were posed by the limited width of the flume.

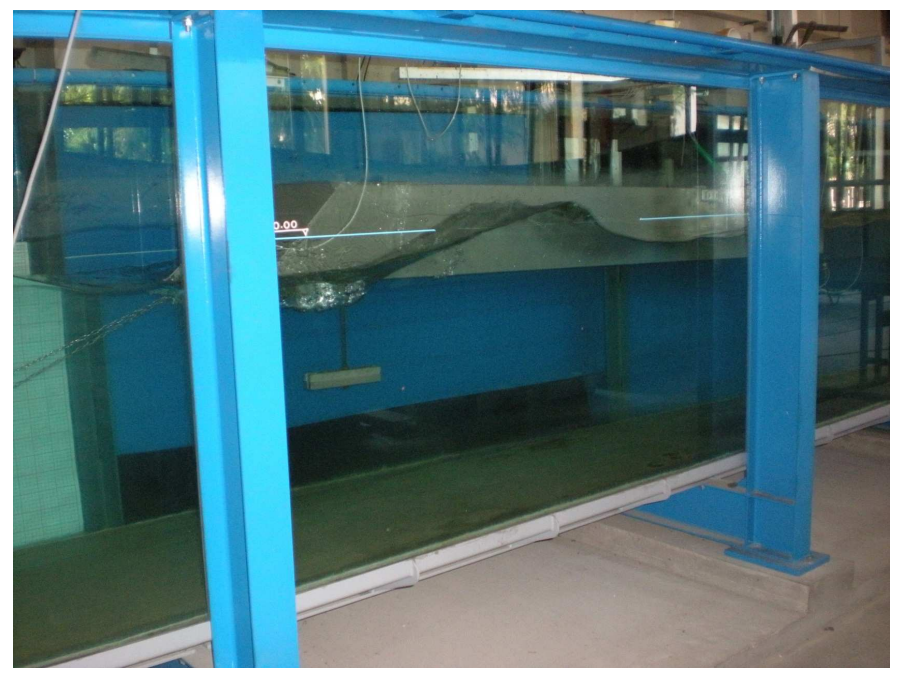

Figure 8. The SeaBreath tested in the wave flume at Padova University. 

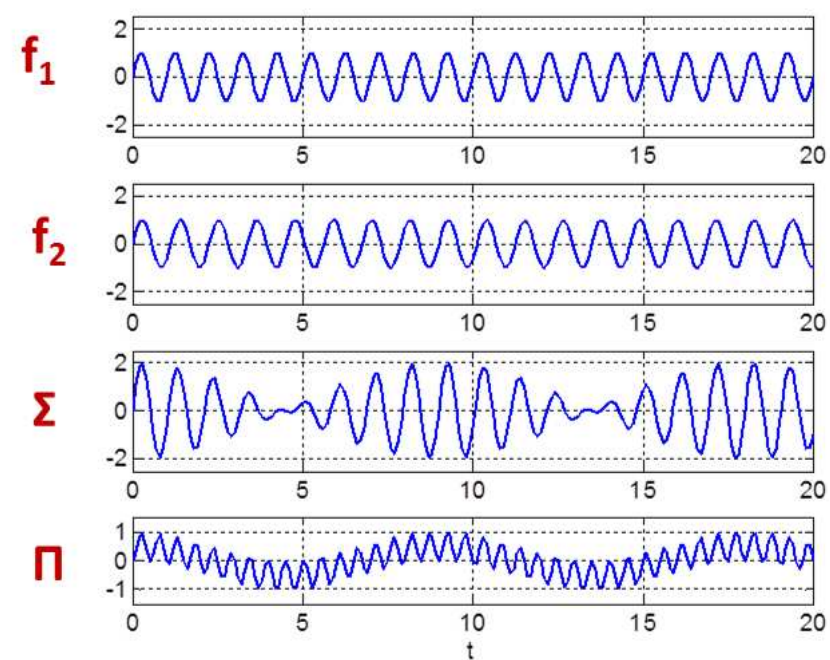

Figure 9. Example of product of two waves

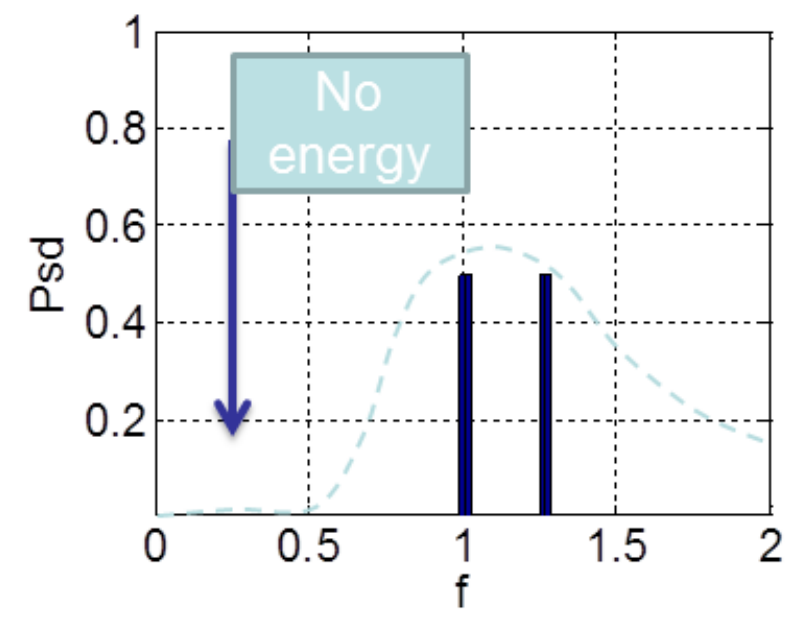

Figure 10. As a consequence of the non-linear dynamics, the response is excited at a frequency where the wave spectrum is flat.

The measurement system allowed the measurement of the incident waves, the low frequency surge displacements of the body and the loads along the chains, with :

-8 resistant type gauges, $60 \mathrm{~cm}$ long;

-displacement meter (Fig. 11), applying a constant load of $700 \mathrm{~g}, 50 \mathrm{~cm}$ span;

-impermeable aluminum load cells, with weight $25 \mathrm{~g}, 25 \mathrm{~kg}$ max force (Fig. 12).

The submerged weight of the four chains is $70 \mathrm{~N} / \mathrm{m}$. The two front chains have a common fairlead (where load cell n. 1 is attached) and diverge for $7^{\circ}$, the length of the chains is $4.16 \mathrm{~m}$. The two rear chains have different fairlead, diverge $5^{\circ}$, and have length $3.95 \mathrm{~m}$. The structure is $2.6 \mathrm{~m}$ long, and the total distance between the front and rear anchors is $10 \mathrm{~m}$. Water depth at the structure is $0.755 \mathrm{~m}$, and elevation of the fairleads is $0.65 \mathrm{~m}$ above the bottom. 


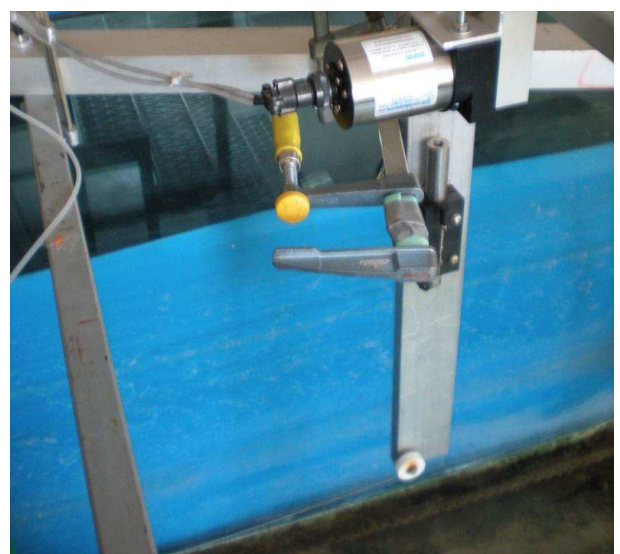

Figure 11. Displacement meter for surge movements: it is a rheometer with a wire mounted vertically and redirected in the horizontal direction by a lower wheel.
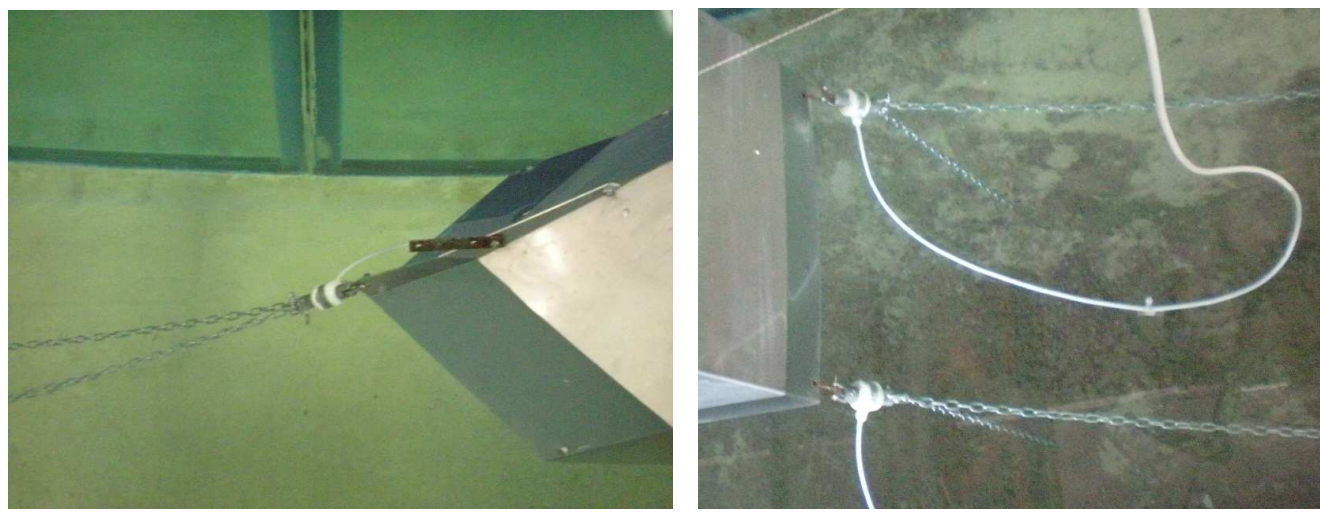

Figure 12. Load cells mounded along the front and rear chains.

\section{Test programme}

The test programme was rather broad (Table 1) but for technical problems in the acquisition system, only part of the measurement files were correctly stored. It is planned that tests will be repeated, possibly with a different floating body.

\begin{tabular}{|c|c|c|c|c|c|}
\hline \multicolumn{2}{|c|}{ Regular wave } & \multicolumn{2}{|c|}{ Bichromatic waves } & \multicolumn{2}{|c|}{ Bichromatic waves } \\
\hline & $\mathrm{H}$ & Tmodulation & $\mathrm{H}$ & Tmodulation & $\mathrm{H}$ \\
\hline $\mathrm{s}$ & $\mathrm{Cm}$ & S & $\mathrm{Cm}$ & $\mathrm{s}$ & $\mathrm{cm}$ \\
\hline 1 & 5 & 6 & 3 & 6 & 15 \\
\hline 1 & 9 & 6 & 6 & 7 & 15 \\
\hline 1 & 10 & 6 & 9 & 7.5 & 15 \\
\hline 1 & 15 & 6 & 12 & 8 & 15 \\
\hline \multirow[t]{3}{*}{1} & 18 & 6 & 15 & 8.5 & 15 \\
\hline & & 6 & 18 & 9 & 15 \\
\hline & & & & 10 & 15 \\
\hline
\end{tabular}




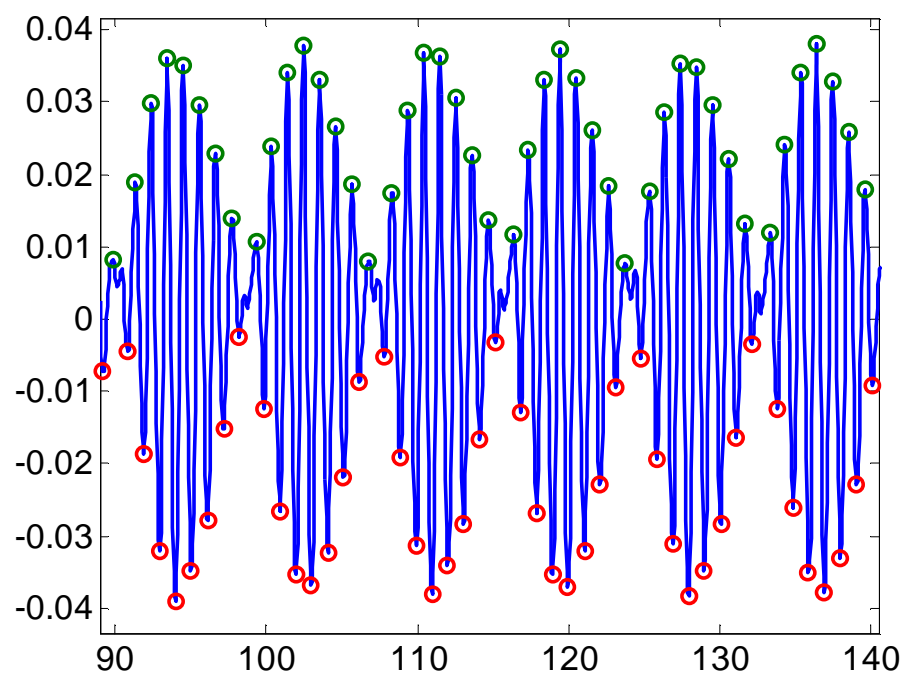

Figure 13. Example of measured surface elevation, with identification of maximum and minimum per each wave (for definition of Hs and Hrms).

\section{Test results}

The tests allow to evaluate the relation between wave and mooring load, for varying periods and wave height. Fig. 14 presents the maximum load recorded at load cell 1 (merging the two front lines) and the incident regular wave height, all with short period (1 s). A typical quadratic relation is found, allowing to evaluate the response in a region that is far from the resonant conditions.

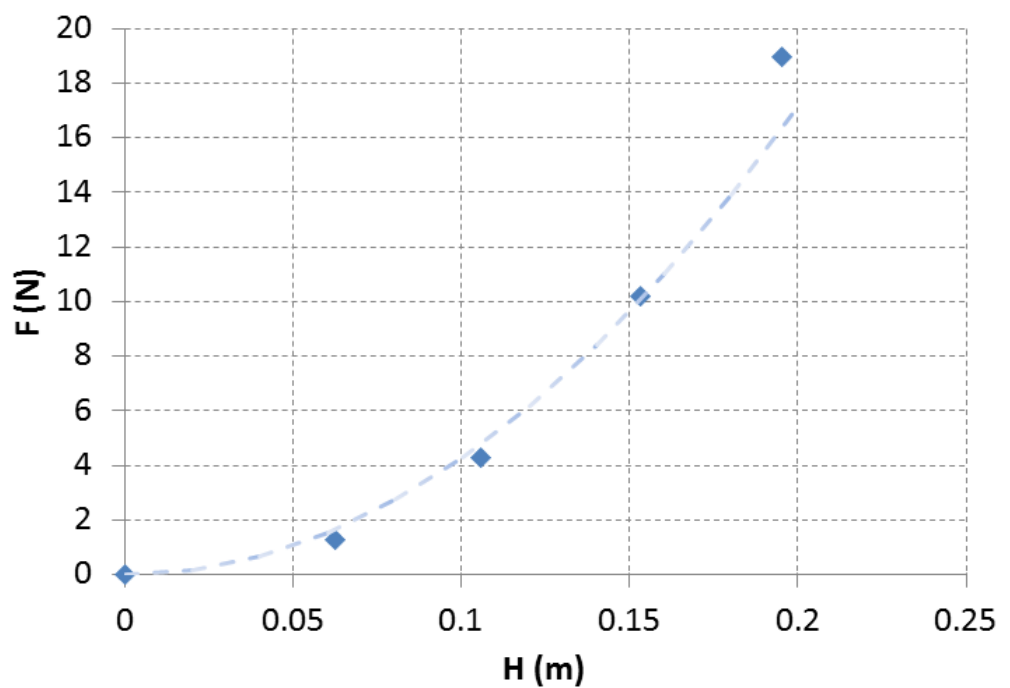

Figure 14. quadratic dependence of the maximum load along the front mooring and the incident wave height.

Fig. 15 shows the maximum load for monochromatic or bichromatic waves with $\mathrm{H}=15 \mathrm{~cm}$. In the $\mathrm{x}$ axis, there is either the main period of the monochromatic wave or the modulation period of the group. It appears evident from the graph, that in resonant conditions ( $8 \mathrm{~s}$ in the model, $36 \mathrm{~s}$ at prototype), the load is increased. 


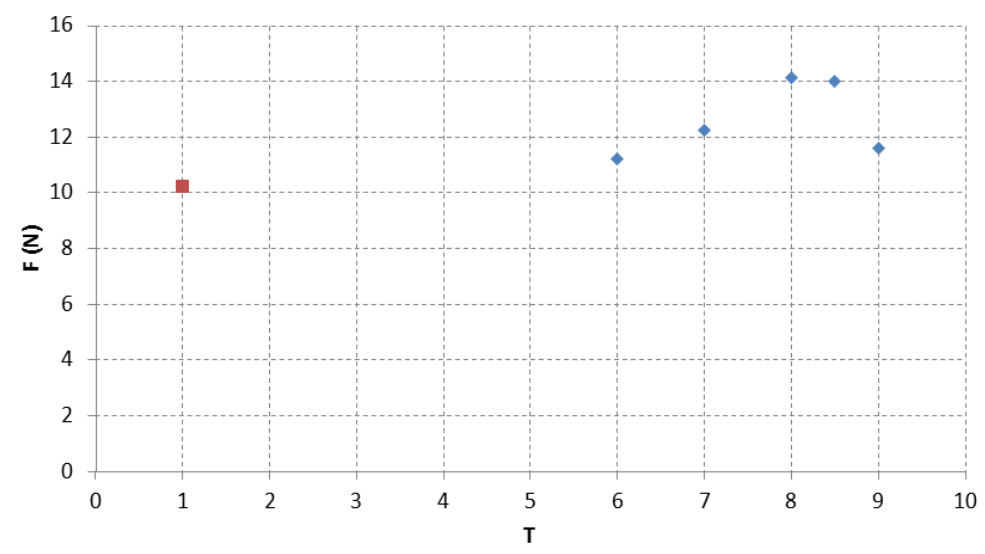

Figure 15. The red point is the load induced by a monochromatic wave, the blue one by the wave superposition of same energetic content (Hrms). Measured eigenperiod in surge is approx. 8s, corresponding to $36 \mathrm{~s}$ in prototype.

\section{CONCLUSIONS}

This note details the design process of the mooring design, with a tentative application to the Seabreath Wave energy converter. Unfortunately the design phase of the mooring system for such device is still at an early stage, since the conditions that should have favored a small scale application at sea were not met (yet).

The note points out a specific set of physical model tests that may be considered to be very useful for the mooring design: the tests include mono and bi-chromatic waves aiming at pointing out the mooring system response at resonant conditions.

Such kind of tests were carried out for the Seabreath device, and showed that at resonance conditions the loads appear to be $40 \%$ larger.

\section{ACKNOWLEDGMENTS}

The partial supports of Merighi Group, of the inventor of SeaBreath (Dott. Luigi Rubino), and of the European Commission through Contract 244104 THESEUS FP7.2009-1 Project, are gratefully acknowledged.

\section{REFERENCES}

Andersen K.H., (2009): Bearing capacity under cyclic loading - offshore, along the coast, and on land. The 21 st Bjerrum Lecture presented in Oslo, 23 November 2007. Canadian Geotechnical Journal, 46, 513-535.

Fitzgerald J., (2009): Position mooring of wave energy converters, PHD thesis at the Chalmers Univerisity of Technology, Goteborg, Sweden.

Harris R.E., Johanning L., Wolfram J., (2004): Mooring systems for wave energy converters: A review of design issues and choices, Heriot-Watt University, Edinburgh, UK.

Isaacson M., Nwogu O.U., (1987): Wave loads and motions of long structures in directional seas. Journal of Offshore Mechanics and Arctic Engineering, 32, 109-126.

Kreuzer E., Wilke U. (2003): Dynamics of mooring systems in ocean engineering, Archive of Applied Mechanics 73, $270-281$ Springer-Verlag.

Loukogeorgaki E., Angelides D., (2005): Stiffness of mooring lines and performance of floating breakwater in three dimensions. Applied Ocean Research 2005; 27(4-5):187-208.

Martinelli L., Lamberti A., Ruol P., Ricci P., Kirrane P., Fenton C., Johanning L., (2010a): Power Umbilical for Ocean Renewable Energy Systems - Feasibility and Dynamic Response Analysis, Proc. ICOE 2010, Bilbao, 6-8 October 2010.

Martinelli L., Spiandorello A., Lamberti A., Ruol P., (2010b): Dynamic Model for Catenary Mooring: Experimental Validation of the Wave Induced Load. Proc. Comsol Conference 2010, Paris, November 2010.

Martinelli L., (2011): WECS under mild wave climates, Proc. OCEANS '11, Kona, Hi, USA, 19-22 Sett. 2011.

Pinkster J. A., (1980): Low Frequency Second Order Wave Excitation Forces on Floating Structures. PhD Thesis, TU Delft, 204 pp.

Wong P., Gaudin C., Randolph M.F., Cassidy M.J., Tian Y., (2012): Performance of Suction Embedded Plate Anchors in Permanent Mooring Applications. Proc. ISOPE. Rhodes June 17-22, 2012. 